\title{
Rethinking Omics Education in Brazil and South America: From Genomics to Multiomics and Critical Policy Studies
}

\author{
Alberto M.R. Dávila
}

\section{Perspective}

G ENOMICS HAS A STORIED PAST DATING BACK TO THE 20TH CENTURY, and impacted on discovery and translational science in medicine, ecology, and bioengineering, to mention but a few (Cuadrat et al., 2016). But the field of genomics has also been changing with the sands of time. Gone are the days when high-throughput technologies were limited to genomics. We now have multiomics discovery platforms including and beyond genomics such as metabolomics, proteomics, glycomics, among others (Gabius, 2018). Multiomics approach to integrative biology offers a fresh and exciting conceptual lens so as to triangulate data across the biological cascade from genes to proteins to metabolites and beyond. Such triangulation of data streams is at the core of contemporary multiomics systems science (Kunej, 2019).

Historically, applications of genomics have been varied ranging from personalized medicine to biotechnology products harnessed from the microbiome of extreme environments (Jorquera et al., 2019). These efforts are now being progressively expanded to the realm of multiomics inquiry. At the same time, such multipronged omics technology advances are highlighting the parallel need for omics education early in the course of the training of next-generation scholars, for example, with a focus on data science in undergraduate biology (Porter and Smith, 2019). Whitley et al. (2020) reviewed the importance of and needs for genomic education among academic, professional, and public platforms, thus underscoring the need to address the societal and educational dimensions of omics sciences that ought to extend beyond genomics.

In a context of genetics and genomics, the \#GenomicDay initiative is spearheaded by the Computational and Systems Biology Laboratory of the Oswaldo Cruz Foundation (FIOCRUZ), a leading biomedical research institution in South America. This initiative was inspired by "Teaching the Genome Generation" developed by the Jackson Laboratory (LaRue et al., 2018; The Jackson Laboratory, 2020). In essence, \#GenomicDay aims to encourage and engage broad public interest in genome sciences through critically informed science outreach and teaching the basic concepts of DNA, genes, and genomes and their various applications in health and society broadly.

Using accessible and relatable language, \#GenomicDay seeks to reach out to high school students and teachers through a variety of communication strategies, such as lectures and creating hands-on formal and informal learning spaces. Because such initiatives engage science with scholars and high school students in an "upstream" formative early age and context, they conjure up new vistas and help imagine broadly framed multiple possible professional trajectories and creative careers in science and society in young minds.

The first edition of the \#GenomicDay was successfully organized in October 2016 in Rio de Janeiro (FIOCRUZ, 2016). Owing to interest and relevance for high school students, additional \#GenomicDay editions were annually organized in several regions of Brazil. The fifth edition initially planned for late 2020 will involve at least 20 high schools distributed nationwide representing the five regions of Brazil; for the first time, on-site sequencing will be carried in schools using sequencing technologies.

Because of the current Coronovirus Disease-2019 (COVID-19) pandemic, a need to properly inform society about omics and multiomics approaches in use for research on Severe acute respiratory syndrome coronovirus 2 (SARSCoV-2), clinical studies, drugs, and vaccines was identified as a priority. Hence, a blog site akin to a science journalism and knowledge translation effort, containing short summaries using accessible and relatable language was created and named \#GenomicNews (http://genomicnews .biowebdb.org).

Computational and Systems Biology Laboratory, Graduate Program in Biodiversity and Health, Oswaldo Cruz Institute, Fiocruz, Rio de Janeiro, Brazil.

(C) Alberto M.R. Dávila, 2020. Published by Mary Ann Liebert, Inc. This Open Access article is distributed under the terms of the Creative Commons License (http://creativecommons.org/licenses/by/4.0), which permits unrestricted use, distribution, and reproduction in any medium, provided the orginal work is properly credited. 
After 4 years of organizing \#GenomicDay, we are thus finally prepared to offer a complementary state-of-the-art initiative, one short-term hands-on course directed to high school teachers, communication and social media professionals, and physicians: \#GenomicWeek. The goal of the latter initiative is to help knowledge mobilization for the concepts of DNA, genes, and genomes and their different application and impacts in society among professionals.

Looking further, it is conceivable that \#GenomicDay, \#GenomicNews, and \#GenomicWeek can usefully serve as the home base for genomics and multiomics citizen science initiatives in Brazil, including and enhancing interactions with similar initiatives elsewhere in South America. For example, in 2018, the "1000 Genomas Chile" (http://www.1000genomas.cl/concurso2019) selected 10 high schools in Chile to sequence the genome of an Oniscidea species, to build a regional network for knowledge mobilization in genomics.

As the field has now evolved into multiomics science, an urgent need to scale up such knowledge mobilization efforts beyond genomics has become palpable. I propose that omics systems science stands to benefit, as with Brazil and South America, by extending the above vision on science education and outreach to a broader multitechnology context.

Still, science and technology outreach, alone, is not sufficient to cultivate critical thinking skills essential for any successful career in science and society (Fisher et al., 2010). One concept that holds vast potential but has not yet been enacted upon is the idea that science careers also include those in technology and innovation policy. Students in high school can benefit from learning the career options available to them in science beyond the laboratory space that impacts upon the broader society such as technology and innovation policy, but in ways that are critically informed (Sarewitz, 2016; Sclove, 2020).

That is, innovation policy requires thinking not only of scientific knowledge but also of epistemology of knowledge, that is, how do we know what we know? As students learn introductory concepts in science and technology policy, they can then begin to appreciate that how we frame a given field of research (i.e., epistemology) matters greatly for both laboratory work and science policy (Frodeman, 2020). For example, and as noted earlier in this perspective, framing systems science through genomics or multiomics lens determines whether and to what extent we incorporate complementary or alternative technologies relevant to answer the questions we pose in science.

The field of critical policy studies aims to address precisely these sorts of questions and helps cultivate a culture of curiosity and scientific inquiry that seeks out not only new scientific knowledge but also questions how that knowledge is framed in the first place (Von Schomberg, 2019). By shifting our attention in science education and outreach to a broader and more critical realm as already noted, technology and innovation policy in medicine, biology, and ecology in Brazil and South America can be harnessed more efficiently, and in ways attuned to broader societal values, by engaging with multiomics science education and the field of critical policy studies (Frodeman, 2020; Sclove, 2020; Von Schomberg, 2011; Von Schomberg and Hankins, 2019).

\section{Acknowledgments}

I would like to thank Roney Coimbra, Eduardo Volotão, Ana Paula Assef, Guilherme Matos, Tainá Raiol, Amanda Perse, Felipe Naveca, Flábio Araújo, Gabriel Ferreira, Gláucia Marcon, Leonardo Koerich, Darueck Campos, Ademir Martins Jr., Fábio Aguiar-Alves, Humberto M. Garay-Malpartida, Glauber Wagner, Antonio Rezende, and Rodrigo Pereira for the \#GenomicDay coordination in their cities over the past years, as well as to the many academic colleagues who enthusiastically and creatively contributed to the theoretical and practical classes to high school students. I also thank Miguel Allende for helpful discussions on teaching genomics in high school, and Rodrigo Jardim and Nelson Kotowski for the valuable help with \#GenomicsNews.

\section{Disclaimer}

The views expressed are the personal opinions of the author only.

\section{Author Disclosure Statement}

The author declares there are no conflicting financial interests.

\section{Funding Information}

No funding was received for this article.

\section{References}

Cuadrat RR, Ferrera I, Grossart HP, and Dávila AM. (2016). Picoplankton Bloom in Global outh? A high fraction of aerobic anoxygenic phototrophic bacteria in metagenomes from a Coastal Bay (Arraial do Cabo-Brazil). OMICS 20, 76-87.

FIOCRUZ. (2016). \#GenomicDay, Rio de Janeiro. http://www .fiocruz.br/ioc/cgi/cgilua.exe/sys/start.htm?infoid=2637\&sid= 32. Accessed April 26, 2020.

Fisher E, Biggs S, Lindsay S, and Zhao J. (2010). Research thrives on integration of natural and social sciences. Nature 463, 1018 .

Frodeman R. (2020). What happens when society emphasizes technical education and treats the humanities as irrelevant? The Dallas Morning News, February 3rd. https://www.dallas news.com/opinion/commentary/2020/02/03/what-happenswhen-society-emphasizes-technical-education-and-treats-thehumanities-as-irrelevant. Accessed April 26, 2020.

Gabius HJ. (2018). The sugar code: Why glycans are so important. Biosystems 164, 102-111.

Jorquera MA, Graether SP, and Maruyama F. (2019). Bioprospecting and biotechnology of extremophiles. Front Bioeng Biotechnol 7, 204.

Kunej T. (2019). Rise of systems glycobiology and personalized glycomedicine: why and how to integrate glycomics with multiomics science? OMICS 23, 615-622.

LaRue KM, McKernan MP, Bass KM, and Wray CG. (2018). Teaching the genome generation: Bringing modern human genetics into the classroom through teacher professional development. J STEM Outreach 1, 48-60. 
Porter SG, and Smith TM. (2019). Bioinformatics for the Masses: The need for practical data science in undergraduate biology. OMICS 23, 297-299.

Sarewitz D. (2016). Saving science. New Atlantis 49, 4-40. https://www.thenewatlantis.com/publications/saving-science. Accessed April 26, 2010.

Sclove R. (2020). Democracy and technology: An interview with Richard Sclove from Beth Simone Noveck. Digit Gov Res Pract 1, Article 5.

The Jackson Laboratory. (2020). Teaching the genome generation. https://www.jax.org/education-and-learning/high-schoolstudents-and-undergraduates/teaching-the-genome-generation. Accessed April 26, 2020.

Von Schomberg R. (2011). On identifying plausibility and deliberative public policy: Commentary on: "Negotiating plausibility: Intervening in the future of nanotechnology." Sci Eng Ethics 17, 739-742.

Von Schomberg R. (2019). Why responsible innovation? https:// app.box.com/s/h8gib5ga6wtcv81dste3kjlhyz1zpu91. Accessed April 26, 2020.
Von Schomberg R, and Hankins J. (2019). International Handbook on Responsible Innovation. A Global Resource. Cheltenham and Northampton, UK: Edward Elgar Publishing. Whitley KV, Tueller JA, and Weber KS. (2020). Genomics education in the era of personal genomics: Academic, professional, and public considerations. Int J Mol Sci 21, pii:E768.

Address correspondence to: Alberto M.R. Dávila, DSc Computational and Systems Biology Laboratory Graduate Program in Biodiversity and Health Oswaldo Cruz Institute, Fiocruz. Av Brasil 4365

Rio de Janeiro RJ 21040-900

Brazil

E-mail: alberto.davila@ fiocruz.br 